\title{
EDITORIAL La década de las Terapias Contextuales
}

\author{
Jorge Barraca Mairal \\ Universidad Camilo José Cela
}

Cuando este monográfico de Análisis y Modificación de Conducta salga a la luz habrá transcurrido casi una década desde que otro semejante se publicase. En aquel octubre de 2006, la revista EduPsykhé invitaba a los principales autores y divulgadores de las Terapias de Tercera Generación de España (Marino Pérez Álvarez, Carmen Luciano, Antonio Fernández Parra, Rafael Ferro, Miguel Ángel Vallejo, Azucena García Palacios, Rafael Morón, Antonio García Higuera, etc.) a enviar un artículo en la terapia en la que eran referentes. El número que agrupó estos trabajos bajo el título genérico de “Últimos desarrollos de la Terapia de Conducta (ante la tercera generación)" significó un hito para el conocimiento en nuestro país de estas terapias y se convirtió en cita inevitable para todo aquel que quisiera disponer de una panorámica sobre las entonces novedosas y mal conocidas terapias de esta corriente.

Sin embargo, ya entonces el autor de estas líneas señalaba que estas terapias ni eran tan nuevas, ni sus contribuciones tan rompedoras que no se encontrasen, en muchos casos, en planteamientos anteriores (bien en generaciones previas de la misma terapia de conducta, bien en las aportaciones de otras tradiciones terapéuticas). Y es que, sin duda, lo diferente y llamativo ha sido su expansión a lo largo de estos últimos diez años. El interés que han despertado, la increíble proliferación de artículos, libros, instrumentos, cursos, talleres, seminarios, congresos, másteres, vídeos, supervisiones, etc. que se han sucedido sin interrupción desde entonces. Este movimiento revela que el campo profesional y académico de la Psicología estaba por fin preparado para acogerlas, entenderlas e incluso entusiasmarse por ellas. Como en su día afirmase Gustav Mahler de su música -que sería comprendida en el siguiente siglo- parece que la última ola de la terapia conductual no ha requerido cien pero al menos sí diez años para penetrar y agradar en los oídos de los actuales psicólogos.

Claro que en este camino se han producido igualmente las mutaciones, las desviaciones del original $y$, por qué no decirlo, las deserciones. Una avalancha de información como la acontecida no puede sino arrastrar consigo también trabajos errados, visiones superficiales y mezclas eclécticas de las que no siempre es fácil deslindarse. En el afán por situar las cosas en su sitio, este número pretende volver a ofrecer una información bien contrastada de la realidad de las terapias contextuales, denominación que ha acabado por resultar más adecuada y por imponerse sobre los primeros usos que priorizaban la denominación "tercera ola" o "tercera generación" y que por esa razón es la que empleamos aquí como aglutinador.

Naturalmente, plantearse una actualización de los mismos trabajos tras estos diez años carecía de sentido: la evolución del campo y los nuevos intereses imponían una alternancia de contenidos y, en algunos casos, también de autores. Por eso, en esta ocasión, se repiten nombres fundamentales para la investigación en España, como son los de Marino Pérez Álvarez, Carmen Luciano o Rafael Ferro, pero por la pujanza de sus investigaciones aparecen ahora los de José Manuel García Montes, Joaquim Soler, Luis Valero, Miguel Ángel López Bermúdez o Carlos Francisco Salgado. 
En primer lugar, el artículo de la Profesora Carmen Luciano supone una lección magistral sobre la historia y la actualidad de ACT, que culmina recalcando la necesidad de no perder nunca el referente que supone el contextualismo funcional raíz de todas estas terapias y principio al que los investigadores de ellas deben remitirse si desean seguir asentando sus trabajos sobre bases bien fundamentadas científicamente.

A continuación, con el deseo manifiesto de ofrecer un cierto contrapunto, el artículo del autor de este editorial toma un camino muy diferente y presenta la actualidad de la terapia de Activación Conductual desde un enfoque aplicado, en el anhelo de volver más próximo este modelo y presentarlo de manera que también los psicólogos clínicos puedan disponer de una guía sencilla para implementarlo en sus consultas.

La actualización de la Terapia Dialéctica Conductual de Marsha Linehan es fruto de la colaboración de Joaquim Soler, Matilde Elices y Cristina Carmona, que, además de recordar el modelo original, centran su labor en una excepcional revisión actualizada de los trabajos empíricos que desvelan qué componentes de esta terapia son los más prometedores y los que las investigaciones consideran más eficientes para el tratamiento de esta condición clínica tan retadora.

Por su parte, los clínicos e investigadores Rafael Ferro García, Luis Valero Aguayo y Miguel Ángel López Bermúdez llevan a cabo una modélica presentación de la Psicoterapia Analítica Funcional (FAP), con la que resulta inevitable relacionarlos en España y a nivel internacional por sus magníficas y ya muy extensas contribuciones en esta terapia, entre las que debe señalarse un manual original de muy reciente publicación y la elaboración y adaptación de instrumentos para la evaluación de una práctica profesional competente dentro de la FAP. Los ejemplos y los diálogos terapéuticos del artículo aquí contenido lo convertirán de nuevo en un referente para comprender la terapia en toda su extensión.

En el afán de combinar académicos con psicólogos aplicados, y de incluir también un trabajo empírico en este número, se incluye a continuación el artículo de Carlos Francisco Salgado, que supone una aportación excepcionalmente interesante por cuanto compara -para el caso de pacientes mentales graves- dos de las intervenciones más características de las terapias contextuales: el Mindfulness y la Terapia de Aceptación y Compromiso (ACT). Los resultados, aunque deben tomarse con la lógica cautela por la extensión y características de los participantes, no dejarán de sorprender a aquellos que ponen toda su confianza en la práctica del mindfulness.

El número se cierra con la colaboración de los profesores José Manuel García Montes y Marino Pérez Álvarez, pioneros absolutos en la publicación de una aplicación de la ACT en pacientes psicóticos. Después de muchos años de actividad en la fundamentación e investigación en este campo brindan aquí un trabajo excepcional por su amplitud y detalle -también incorporando unos diálogos impagables para la comprensión de este acercamiento- respecto al uso de ACT en la esquizofrenia. La profundidad y extensión de sus reflexiones suponen sin duda un broche muy valioso para el monográfico.

No cabe duda de que quedarían muchos otros trabajos por incluir y muy distintos autores que han participado en la investigación y diseminación de las terapias contextuales. En particular, las aportaciones de la Terapia Integral de Pareja o una actualización en las aplicaciones del mindfulness, habrían tenido igualmente su justa cabida, pero la extensión posible para este volumen nos ha obligado -ciertamente, no sin dolor- a tener que cerrar en un punto dado esta recapitulación. No obstante, sí se ha planteado que los trabajos aquí contenidos no se limitaran a unas pocas páginas en las que resultara imposible contener toda la riqueza de estos planteamientos. Por eso, antes que añadir otros trabajos sin la necesaria garantía, hemos optado por permitir que los que se incluyeran tuvieran el espacio suficiente para dar buena cuenta de lo importante. Esperamos en que este monográfico tenga el éxito de su predecesor y confiamos en que podemos aprender aún más de lo que hicimos diez años atrás. 